\title{
Staphylococcus aureus genotype B and other genotypes isolated from cow milk in European countries
}

\author{
A. Cosandey, ${ }^{*} \dagger$ R. Boss, ${ }^{*}$ M. Luini,‡ K. Artursson, $§$ M. Bardiau,\# F. Breitenwieser,ll E. Hehenberger, $\dagger$

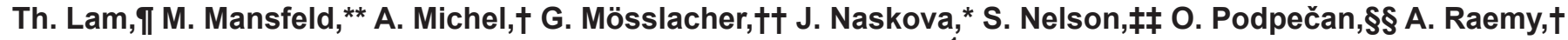 \\ E. Ryan,\#\# O. Salat,IIII P. Zangerl, $\mid$ T A. Steiner,† and H. U. Graber*1 \\ ${ }^{*}$ Agroscope, Institute for Food Sciences (IFS), Schwarzenburgstrasse 161, 3003 Berne, Switzerland \\ †Clinic for Ruminants, Department of Clinical Veterinary Medicine, Vetsuisse-Faculty, University of Berne, Bremgartenstrasse 109a, \\ PO Box 8466, 3001 Berne, Switzerland \\ łlstituto Zooprofilattico Sperimentale della Lombardia e dell'Emilia Romagna, Via Einstein, 26900 Lodi, Italy \\ §Department of Bacteriology, National Veterinary Institute, SE-751 89 Uppsala, Sweden \\ \#Bacteriology, Department of Infectious Diseases, Faculty of Veterinary Medicine, University of Liège, Avenue de Cureghem 6, 4000 Liège, \\ Belgium \\ IMilchprüfring Baden-Württemberg e. V., Marie-Curie-Strasse 19, 73230 Kirchheim/Teck, Germany \\ IGD Animal Health, Arnsbergstraat 7, PO Box 9, 7400 AA Deventer, the Netherlands \\ ${ }^{* *}$ Carinthian Institute for Veterinary Disease Control, Kirchengasse 43, 9020 Klagenfurt, Austria \\ ††Animal Health Organisation Upper Austria, Bahnhofplatz 1, 4021 Linz, Austria \\ $\ddagger \ddagger D$ epartment of Production Animal Clinical Sciences, Norwegian School of Veterinary Science, Ullevalsvn 72, PO Box 8146 Dep, N-0033 Oslo, \\ Norway

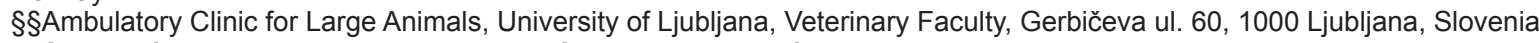 \\ \#\#School of Veterinary Medicine, University College Dublin, Belfield, Dublin 4, Ireland \\ IIIIVeterinary Clinic of Haute Auvergne, Allauzier, 15100 Saint Flour, France \\ ๆTFFederal Institute for Alpine Dairying BAM, 6200 Jenbach, Austria
}

\section{ABSTRACT}

Staphylococcus aureus is globally one of the most important pathogens causing contagious mastitis in cattle. Previous studies, however, have demonstrated in Swiss cows that Staph. aureus isolated from bovine intramammary infection is genetically heterogeneous, with Staph. aureus genotype B (GTB) and GTC being the most prominent genotypes. In addition, Staph. aureus GTB was found to be contagious, whereas Staph. aureus GTC and all the remaining genotypes were involved in individual cow disease. The aim of this study was to subtype strains of Staph. aureus isolated from bovine mastitic milk and bulk tank milk to obtain a unified view of the presence of bovine staphylococcal subtypes in 12 European countries. A total of 456 strains of Staph. aureus were subjected to different typing methods: ribosomal spacer PCR, detection of enterotoxin genes, and detection of gene polymorphisms (lukE, coa). Major genotypes with their variants were combined into genotypic clusters (CL). This study revealed 5 major CL representing $76 \%$ of all strains and comprised CLB, CLC, CLF, CLI, and CLR. The clusters were characterized by the same genetic properties as the Swiss isolates, demonstrating high

Received March 18, 2015.

Accepted September 14, 2015.

${ }^{1}$ Corresponding author: hansulrich.graber@agroscope.admin.ch clonality of bovine Staph. aureus. Interestingly, CLB was situated in central Europe whereas the other CL were widely disseminated. The remaining $24 \%$ of the strains comprised 41 genotypes and variants, some of which (GTAM, GTBG) were restricted to certain countries; many others, however, were observed only once. Key words: Staphylococcus aureus, bovine intramammary infection, genotyping, virulence gene, Europe

\section{INTRODUCTION}

Staphylococcus aureus is the most important pathogen responsible for contagious IMI in cattle worldwide (Sears and McCarthy, 2003). A study by Fournier et al. (2008) demonstrated in Swiss cows that Staph. aureus isolated from bovine IMI is a genetically heterogeneous group. By PCR amplification of the 16S-23S rRNA intergenic spacer region (ribosomal spacer-PCR, RS-PCR), 17 genotypes were detected in 101 epidemiologically independent isolates. Genotype B (GTB) and genotype C (GTC) were most common (80.2\%), whereas the other 15 genotypes occurred rarely, each comprising 1.0 to $4.0 \%$ of all the isolates. The same study and that of Graber et al. (2009) further demonstrated that the genotypes were highly associated with their virulence gene pattern. In particular, Staph. aureus GTB was characterized by the presence of the enterotoxin genes sea, sed, and sej, and a SNP in the 
lukE gene (lukEB). In contrast, Staph. aureus GTC was positive for $s e c$, seg, and tst, and negative for lukEB. The remaining genotypes were heterogeneous in their pattern. The same studies (Fournier et al., 2008; Graber et al., 2009) revealed remarkable differences in IMI prevalence among Staph. aureus GTB, GTC, and the other genotypes: up to $87 \%$ of cows in a herd were infected by strains of GTB and cows typically had 2 or more quarters infected. In the case of GTC and the other genotypes, however, IMI was only found in 1 to 2 cows of a herd, and just 1 quarter of a cow was infected. Staphylococcus aureus GTB is involved in herd problems with high cost in Swiss dairy farming, whereas the remaining genotypes cause IMI of individual cows and are, therefore, financially less problematic. As a consequence, genotyping by RS-PCR, as described by Fournier et al. (2008), allows reliable prediction of the epidemiological type of bovine IMI caused by Staph. aureus.

Besides the RS-PCR of Fournier et al. (2008), other typing methods have been described for subtyping bovine strains of Staph. aureus (Rabello et al., 2007; Hwang et al., 2010; van den Borne et al., 2010; Sakwinska et al., 2011; Tavakol et al., 2012). Two common methods are spa typing (Harmsen et al., 2003) and multilocus sequence typing (MLST; Enright et al., 2000). The former is based on DNA sequencing of the variable spacer region of the staphylococcal spa gene, whereas the latter requires the sequencing of 7 housekeeping genes. Other methods comprise pulsed-field gel electrophoresis or binary typing (Zadoks et al., 2000). All of these methods are effective in obtaining insight into the pathogenesis of bovine IMI caused by Staph. aureus, but their suitability for large clinical investigations is hindered by low throughput and high cost.

The aim of the present study was to subtype strains of Staph. aureus isolated from bovine mastitic milk and bulk tank milk (BTM) to obtain a unified view about the presence of bovine staphylococcal subtypes in 12 European countries. For this purpose, we applied an extended spectrum of typing methods, including RSPCR as conducted by Fournier et al. (2008), analysis of virulence genes, and analysis of the lukEB and coa polymorphisms. We were particularly interested in mapping the presence of Staph. aureus GTB and other genotypes in different countries.

\section{MATERIALS AND METHODS}

\section{Sample Collection}

Twelve European countries participated in this study: Austria, Belgium, France, Germany, Ireland, Italy, Macedonia, the Netherlands, Norway, Slovenia, Sweden, and Switzerland (Figure 1). In total, they contributed 1,685 samples of various types (Table 1 ). They included aseptically collected bovine milk samples from single quarters (SQM), BTM samples collected from the top lid of the tank after previous agitation of the milk for 10 min (NMC, 1999), and strains of Staph. aureus taken from the authors' bacterial culture collections (BC). The BC strains had all been obtained from milk of cows with subclinical IMI using aseptic sample collection.

The BTM and SQM samples were all selected from herds where IMI caused by Staph. aureus had been observed during the past year. The countries and regions delivering BTM samples are listed in Table 1. The SQM samples were obtained from France, Germany, Ireland, Macedonia, Norway, and Slovenia (Table 1). Among these countries, cows of the herds to be sampled were selected according to different criteria, including, at maximum, all lactating cows of a herd or, at minimum, the quarters positive by California Mastitis Test (CMT). Regardless of the selection criterion, however, SQM samples were collected aseptically. Cows with clinical mastitis and those under antimicrobial treatment were excluded. The SQM and BTM samples originated from 231 farms. The Swiss strains were taken from the authors' strain collection, of which a random subset of Staph. aureus GTB $(\mathrm{n}=39)$ and GTC $(\mathrm{n}=$ 32 ) was included in the present study. For the other Swiss genotypes, all available strains of the strain collection were used $(\mathrm{n}=15)$.

After collection of the SQM and BTM samples, they were stored at $-20^{\circ} \mathrm{C}$ until they were transported to the central laboratory where storage was continued at $-20^{\circ} \mathrm{C}$ until further use. During transport to the laboratory, they were kept frozen using styrofoam boxes and dry ice (for long distances) or wet ice (for short distances). The strains from outside of Switzerland were received as cultures or swabs. They were transported at room temperature and stored at $4^{\circ} \mathrm{C}$ until use within $5 \mathrm{~d}$.

\section{Bacteriological Culturing}

The SQM and BTM samples were thawed and warmed to $37^{\circ} \mathrm{C}$ for $10 \mathrm{~min}$ in a water bath and gently mixed to obtain a homogeneous suspension. The SQM samples of each herd were then pooled by adding equal volumes $(500 \mu \mathrm{L})$ to a common tube to create an SQM pool. Thirty microliters of each SQM pool or BTM was plated on CHROMagar Staph. aureus plates (CHROM, CHROMagar, Paris, France) and incubated at $37^{\circ} \mathrm{C}$ for $24 \mathrm{~h}$. This culture medium was recently shown to have excellent diagnostic properties for Staph. aureus isolated from cow milk (Graber et al., 2013). 
Table 1. European survey on Staphylococcus aureus in cow milk: participating countries

\begin{tabular}{|c|c|c|c|c|}
\hline \multirow[b]{2}{*}{ Country (region) } & \multicolumn{2}{|r|}{ Sample } & \multicolumn{2}{|c|}{$\begin{array}{l}\text { Total strains analyzed } \\
\text { per country }(\mathrm{n})\end{array}$} \\
\hline & $\mathrm{n}$ & Type $^{1}$ & IMI & BTM \\
\hline Austria (Kärnten) & 62 & $\mathrm{BC}$ & 50 & 46 \\
\hline Austria (Oberösterreich) & 44 & $\mathrm{BC}$ & & \\
\hline Austria (Tirol) & 51 & $\mathrm{BC}^{2}$ & & \\
\hline Belgium (Liège) & 20 & $\mathrm{BC}$ & 20 & 0 \\
\hline France (Lozère) & 302 & SQM (8 herds) & 15 & 10 \\
\hline France (Rhône-Alpes) & $\begin{array}{l}7 \\
3\end{array}$ & $\begin{array}{l}\text { BTM } \\
\text { SQM ( } 2 \text { herds) }\end{array}$ & & \\
\hline Germany (Niedersachsen) & 42 & BTM & 5 & 95 \\
\hline Germany (Baden-Württemberg) & 53 & BTM & & \\
\hline Germany (Thüringen) & 15 & BTM & & \\
\hline & 15 & SQM (7 herds) & & \\
\hline Ireland (Laighin) & 403 & SQM (10 herds) & 14 & 0 \\
\hline Italy (Lombardia) & 27 & $\mathrm{BC}$ & 24 & 0 \\
\hline Macedonia (Radoviš) & 5 & SQM (3 herds) & 3 & 0 \\
\hline The Netherlands (Overijssel) & $\begin{array}{l}14 \\
60\end{array}$ & BC & 14 & 25 \\
\hline Norway (Oslo) & 78 & SQM (21 herds) & 12 & 0 \\
\hline Slovenia (Ljubljana) & $\begin{array}{r}312 \\
33\end{array}$ & $\begin{array}{l}\text { SQM (3 herds }) \\
\text { BC }\end{array}$ & 13 & 0 \\
\hline Sweden & 53 & $\mathrm{BC}$ & 24 & 0 \\
\hline Switzerland & 86 & $\mathrm{BC}$ & 86 & 0 \\
\hline & 1,685 & & 280 & 176 \\
\hline
\end{tabular}

In parallel to CHROM, $10 \mu \mathrm{L}$ was plated on blood agar (BA, BioMérieux, Geneva, Switzerland) and incubated at $37^{\circ} \mathrm{C}$ for $24 \mathrm{~h}$ to assess bacteria present in the samples. Bacterial strains were directly streaked on $\mathrm{CHROM}$ and BA. The bacteria on BA were judged according to the guidelines of the National Mastitis Council (NMC, 1999) based on morphology, hemolysis, catalase reaction, and Gram stain by a scientist with experience in phenotypic identification of bacteria.

Prior calculations revealed that plating $30 \mu \mathrm{L}$ of SQM pool milk on a CHROM plate (see above) would provide, on average, 13 colonies of Staph. aureus if $7.1 \%$ of the cows were infected by Staph. aureus GTC (i.e., the median cow prevalence for GTC; Fournier et al., 2008) and each infected cow were shedding average amounts of Staph. aureus $(5,900 \mathrm{cfu} / \mathrm{mL}$; Studer et al., 2008). Similar numbers of colonies are expected for genotypes other than GTB and GTC (GTOG) as for GTB and GTC (median cow prevalence $=6.3 \%$; Fournier et al., 2008). For Staph. aureus GTB with a median cow prevalence of $47.2 \%$ (Fournier et al., 2008), 84 staphylococcal colonies would be expected. If SQM pools were prepared from CMT-positive quarters of a herd only, $>100$ colonies of Staph. aureus GTB, GTC, or GTOG would be assumed to be present on the CHROM plate. The considerations made above for SQM pools are also largely valid for BTM samples if the following conditions are fulfilled: (1) the infected gland of the cows is the principal source of Staph. aureus on the farm and other sources are largely negligible (an assumption confirmed by Sears and McCarthy, 2003); and (2) the cows with subclinical IMI are milked into the tank, a practice that is frequently observed in the field.

\section{DNA Extraction}

Pink to dark pink (i.e., mauve) colonies grown on CHROM plates were further used. According to Graber et al. (2013) and the manufacturer (www.chromagar. com), colonies of this color are indicative of Staph. aureus. The SQM pool and BTM samples together provided 150 CHROM plates showing typical colonies. On each plate, 10 mauve colonies (or as many colonies as were available) were randomly picked: on 93 plates, 10 colonies per plate were selected (35 plates from SQM pools/58 plates from BTM); on 15 plates, 6 to 9 (5 SQM pools/10 BTM) colonies were selected; on 29 plates, 2 to 5 (3 SQM pools/26 BTM) colonies per plate were selected, and on 13 plates (all BTM), 1 colony was selected. For BC, 3 colonies were picked. If Staph. aureus GTB was present in SQM pools or BTM ( $\mathrm{n}=$ 16), 10 colonies could always be sampled. In 14 cases, each of the 10 colonies per case was GTB-positive; in 1 case, 9 colonies were GTB-positive; and in 1 case, 7 colonies were GTB-positive.

In total, 2,335 colonies were selected. Each colony was resuspended in $100 \mu \mathrm{L}$ of TEL buffer (10 $\mathrm{m} M$ Tris/ 


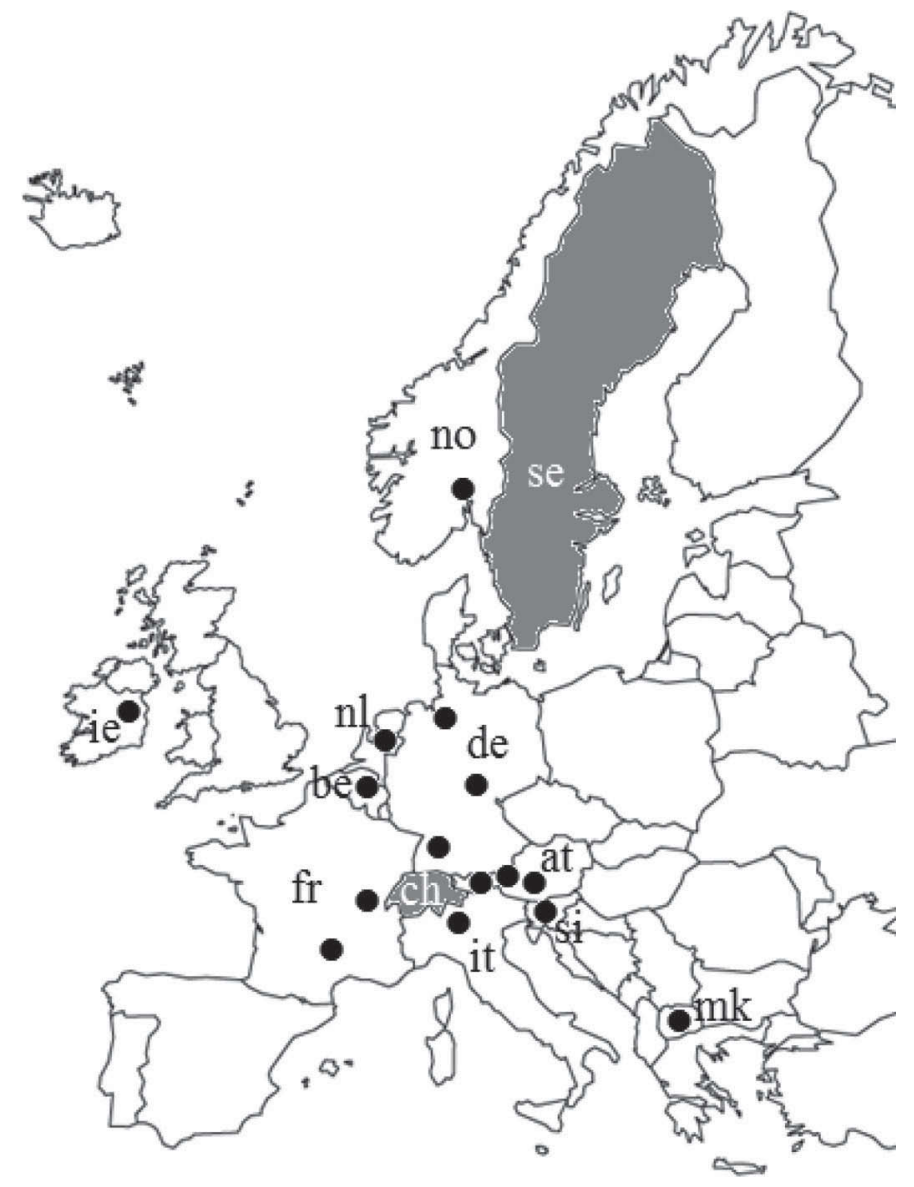

Figure 1. European countries and regions contributing isolates of Staphylococcus aureus to the present study. Bacterial isolates were obtained from milk samples taken in the indicated regions $(\mathbf{0})$; countries shaded in gray indicate sampling of milk throughout the country. at $=$ Austria; be = Belgium; ch $=$ Switzerland; de = Germany; fr $=$ France; ie = Ireland; it = Italy; $\mathrm{mk}=$ Macedonia $; \mathrm{nl}=$ the Netherlands; no = Norway; se $=$ Sweden; si $=$ Slovenia.

$\mathrm{HCl}, 10 \mathrm{~m} M$ EDTA; $\mathrm{pH}=8.5)$, incubated at $95^{\circ} \mathrm{C}$ for $10 \mathrm{~min}$, and immediately placed on ice. The lysates were then diluted 1:100 in $\mathrm{H}_{2} \mathrm{O}$ to be used as templates for the different types of PCR (Table 2). For multiplex PCR, the lysates were further purified as described by Graber et al. (2009), including treatment with mutanolysin and lysozyme followed by DNA extraction using a column. The elution volume was $100 \mu \mathrm{L}$.

\section{Identification by PCR, Genotyping, and Strain Selection}

All DNA samples $(\mathrm{n}=2,335)$ were first analyzed by melting curve PCR ( $\mathbf{P P C R}$ ) for nuc as described by Syring et al. (2012). The nuc gene is highly specific for Staph. aureus (Brakstad et al., 1992; Graber et al., 2007) and was therefore used for definitive identifica- tion of the picked colonies. All nuc-positive isolates were considered to be strains of Staph. aureus and were then genotyped by RS-PCR using a miniaturized electrophoresis system (Agilent Technologies, Santa Clara, CA) as described by Fournier et al. (2008). After genotyping, one representative isolate of each genotype found in each SQM pool, BTM sample, or BC was selected, resulting in a total of 456 strains of Staph. aureus (Table 1). Two hundred eighty strains were obtained from BC and SQM pools, and 176 strains were from BTM. All strains were used for definitive analysis.

New genotypes were named and extended according to Fournier et al. (2008), leading to the genotypes GTA to GTZ, followed by the genotypes GTAA to GTAZ and GTBA to GTBN. An electrophoretic pattern differing in 1 band from an identified genotype was considered a genotypic variant. Variants were indicated by roman numerals in superscript following the name of the genotype (e.g., GTR ${ }^{\mathrm{I}}, \mathrm{GTR}^{\mathrm{II}}$ ). Variation in more than one band was regarded as a new genotype. To identify genotypes and their variants, a recently developed in-house computer program was applied (Syring et al., 2012). Genotypes and their variants isolated from SQM pools and BTM encompassing at least $5 \%$ of all strains were combined into genotypic clusters (CL). Genotypes and their variants were considered to be involved in IMI if the isolates were obtained from aseptically taken milk samples as in the case of the SQM pool or the BC strains.

\section{PCR for Virulence Genes}

Polymerase chain reaction for the coa gene coding for coagulase was performed as described by Fournier et al. (2008). Multiplex PCR for the enterotoxin genes seb, see, and seh was performed using purified lysates and the primers of Monday and Bohach (1999), as described by Graber et al. (2009). Monoplex mPCR was run for sea, sec, sed, seg, sei, sej, and tst (coding for the toxic shock syndrome toxin-1). For all these $\mathrm{mPCR}$, the total volume was $20 \mu \mathrm{L}$ containing $300 \mathrm{nM}$ of both primers (Table 2), 1× Kapa Sybr Fast (Kapa Biosystems Inc., Woburn, MA), and $2.5 \mu \mathrm{L}$ of $1: 100$ diluted DNA template. The mPCR run began with an initial step at $95^{\circ} \mathrm{C}$ for 3 min, followed by 35 cycles of denaturation at $95^{\circ} \mathrm{C}$ for $3 \mathrm{~s}$, annealing and extension in a single step at $60^{\circ} \mathrm{C}$ for $50 \mathrm{~s}$, and a final extension step at $60^{\circ} \mathrm{C}$ for $5 \mathrm{~min}$. In the case of sec, sei, and tst, annealing was performed at $55^{\circ} \mathrm{C}$ for $50 \mathrm{~s}$ followed by extension at $72^{\circ} \mathrm{C}$ for $2 \mathrm{~s}$. Melting of the amplicons was performed between $60^{\circ} \mathrm{C}$ and $94^{\circ} \mathrm{C}$, with increments of $1^{\circ} \mathrm{C}$ and a 5 -s waiting time at each step. The mPCR were run in a Rotor-Gene 6000 real-time thermal cycler (Corbett Life Science, Mortlake, Australia). 
Using mPCR analysis, a single melting peak together with an appropriate melting curve of the positive control was regarded as a positive result for the detected gene. Detection of the SNP lukEB within the lukE gene was performed as described by Boss et al. (2011) using real-time PCR for this target.

\section{Statistical Analysis}

Data were expressed as frequencies or percentages except in the case of the coa amplicons, which were presented as median, minimum, and maximum. After single-factor ANOVA by the Kruskal-Wallis test, the size of coa amplicons was compared among countries using the Mann-Whitney U-test. As in the publication of Fournier et al. (2008), the method of generalized estimating equations (GEE) was used to compare CL among each other based on the analyzed genes. The GEE method was introduced by Liang and Zeger (1986) and allows analysis of longitudinal data or repeated measures, as in the present case. If a Staph. aureus strain showed a positive PCR result for a particular gene or polymorphism it was classified as present (1); otherwise, it was considered absent (0). For the present study, 11 of these binary variables were included in the GEE analysis. The GEE procedure was also applied for comparing the virulence gene patterns among countries (covariate "country") and for comparing the type of sample (covariate "sample type") from which the strains were isolated; $\mathrm{BC}$ strains and strains isolated from SQM pools were coded as 1 (because they are all isolated from bovine IMI), and strains isolated from BTM as 0. These analyses were performed for each CL separately. Computation was performed using the geepack library of the R 3.0.2 statistical software package (R Core Team, 2013). If not otherwise stated, statistical data evaluation was performed using the Systat 13 software (Systat Software Inc., Chicago, IL). Significance was defined at $P<0.05$. For all statistical computations in which multiple testing was necessary, $P$-values were adjusted according to Holm (1979).

\section{RESULTS}

\section{Overview}

In the present study, which included 12 European countries, 456 strains of Staph. aureus (Table 1) were analyzed for genotype, coa polymorphism, lukEB, and virulence gene pattern. In Table 3, the resulting 5 major CL are listed; Table 4 presents all other, rare genotypes ( $\mathrm{n}=41)$ merged to one CL (CLOT).

According to Table 3, CLB, CLC, CLF, CLI, and CLR were the major genotypic clusters, for strains isolated from both SQM pools and BTM. In addition, both types of isolates showed the same clusterdependent virulence gene patterns: CLB was typically positive for sea, sed, sej, and lukEB, and was negative

Table 2. Overview about the different types of PCR performed including template, primers, and probe

\begin{tabular}{|c|c|c|c|c|}
\hline Target $^{1}$ & $\begin{array}{l}\text { Amplicon } \\
\text { size (bp) }\end{array}$ & $\begin{array}{l}\text { Template } \\
\text { DNA }^{2}\end{array}$ & $\begin{array}{l}\text { Primer/probe } \\
\text { names }\end{array}$ & Primer references or sequences \\
\hline \multicolumn{5}{|l|}{ Standard PCR } \\
\hline coa & $\geq 630$ & Diluted & coa- $1 /-2$ & Akineden et al. (2001) \\
\hline \multicolumn{5}{|l|}{ Multiplex PCR } \\
\hline seb, see, seh & & Purified & & Monday and Bohach (1999) \\
\hline \multicolumn{5}{|l|}{ Melting curve PCR } \\
\hline sed & 624 & Diluted & Gsed-S/-AS & Boss et al. (2011) \\
\hline $\operatorname{seg}$ & 644 & Diluted & Gseg-S/-AS & Boss et al. (2011) \\
\hline sej & 332 & Diluted & Gsej-S/-AS & Boss et al. (2011) \\
\hline \multirow[t]{2}{*}{$\mathrm{sec}$} & 236 & Diluted & Gsec-S & 5'-TTG AAG TGC AAA CTG ATA AGA-3' \\
\hline & & & Gsec-AS & 5'-AAC CGT TTT ATT GTC GTT GTA-3' \\
\hline \multirow[t]{2}{*}{ sei } & 444 & Diluted & Gsei-S & 5'-TAT AGA TTT AAA AGG CGT CAC-3' \\
\hline & & & Gsei-AS & 5'-ACT TTC CCI TTA TTA AAA CCT G-3' \\
\hline
\end{tabular}

\footnotetext{
${ }^{1}$ co $a=$ gene coding for coagulase; RS = 16S-23S rRNA intergenic spacer region; sea to sej = genes of Staphylococcus aureus coding for the enterotoxins A to J, respectively; tst = gene coding for the toxic shock syndrome toxin-1; nuc = gene coding for thermonuclease; lukEB = SNP within the lukE gene (coding for leukotoxin E).

${ }^{2}$ Diluted $=$ bacterial lysate was 1:100 dilution with $\mathrm{H}_{2} \mathrm{O}$; purified $=$ the bacterial lysate was further treated with mutanolysin and lysozyme followed by DNA extraction using a filter tube; the elution volume was $100 \mu \mathrm{L}$.
} 
Table 3. Distribution (number of strains involved in IMI [bulk tank milk, BTM]) of virulence genes among the major genotypic clusters (CL) of Staphylococcus aureus

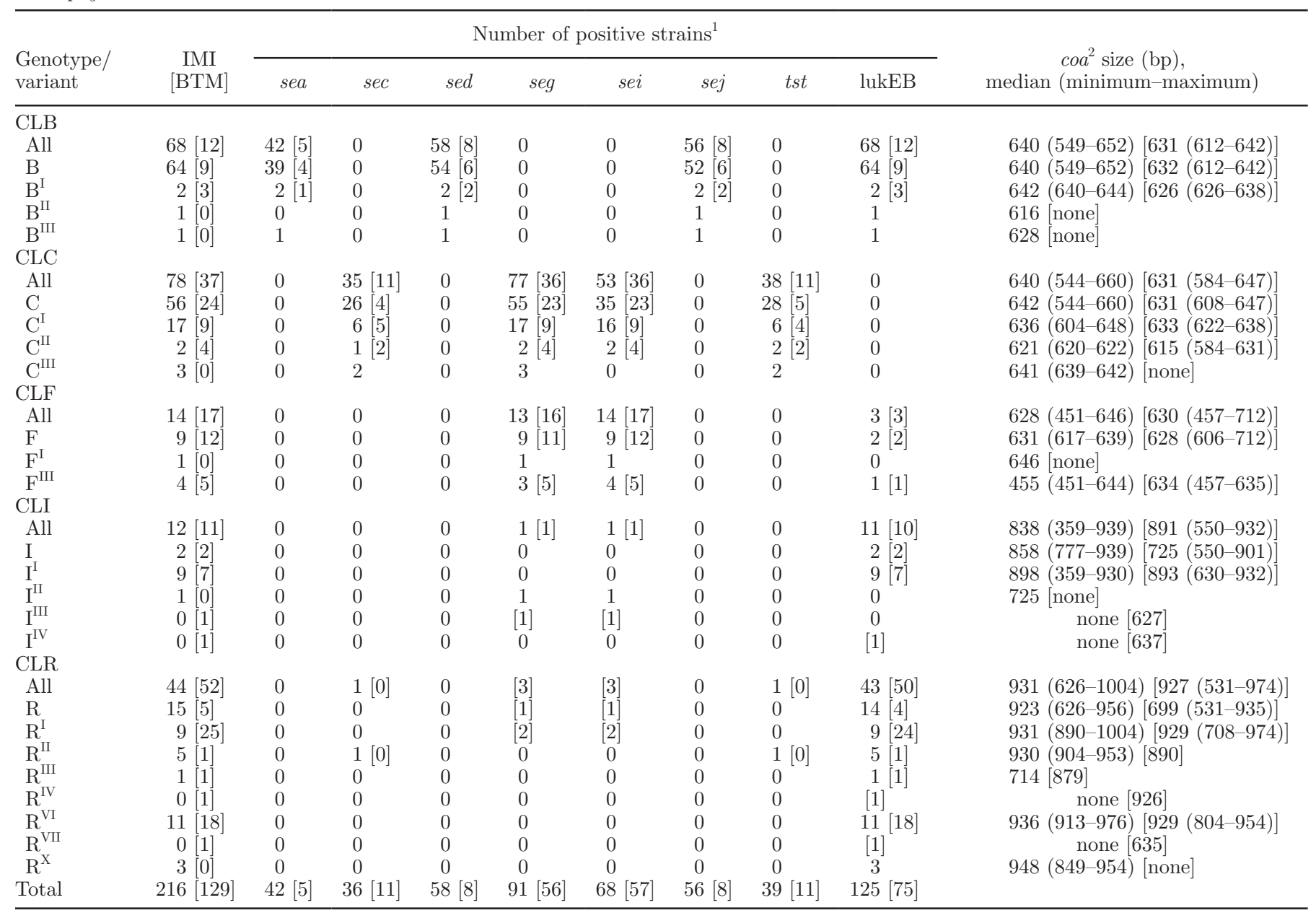

${ }^{1}$ sea to $s e j=$ genes coding for staphylococcal enterotoxins A to J, respectively; tst = gene coding for the toxic shock syndrome toxin-1; lukEB $=\mathrm{SNP}$ within the lukE gene.

${ }^{2}$ coa $=$ gene coding for coagulase of Staphylococcus aureus.

for the other factors, whereas CLC strains were positive for sec, seg, sei, and tst but negative for sea, sed, sej, and lukEB. For CLF, both types of isolates showed a positive result for $s e g$ and $s e i$, but were typically negative for lukEB. In the case of CLI and CLR, the isolates were almost exclusively negative for all the analyzed enterotoxin genes, but were positive for lukEB. In rare cases, strains were positive for sea, seg, or sei (Table 3).

Comparing the different clusters among each other by the statistical GEE procedure, the following results were then obtained: for all comparisons except CLF versus CLOT $(P=0.007)$ and CLI versus CLR $(P=$ $0.238)$, the values of $P$ were always $<0.001$.

\section{Cluster B}

Cluster B strains (overall $\mathrm{n}=80$ ) were observed in 6 countries (Austria, Belgium, France, Germany, Italy, and Switzerland) but were not found in Ireland, Slovenia, Macedonia, Norway, the Netherlands, or Sweden (Table 5). Interestingly, CLB was detected in the south (Baden-Württemberg), but not in north (Niedersachsen) or in the middle (Thüringen) of Germany. Variant GTB $^{\mathrm{I}}$ was found in Switzerland and Germany. For Belgium and Italy, one strain was positive for GTB ${ }^{\mathrm{II}}$ and $\mathrm{GTB}^{\mathrm{III}}$, respectively. All of the CLB strains isolated from SQM pools and BTM were positive for lukEB and many were positive for sea (59\%), sed (83\%), and sej $(80 \%)$. None of the other tested enterotoxin genes were observed, and none of the strains were positive for tst. In addition, we compared the virulence gene patterns of CLB among countries and the type of milk sample from which the isolates were obtained (SQM pool vs. BTM) by the GEE procedure. For the "country" covariate, we obtained a value of $P=0.236$; for the "sample type" covariate, we obtained a value of $P=0.282$. 
Table 4. Distribution (number of strains involved in IMI [bulk tank milk, BTM]) of virulence genes among the other, rare genotypes of Staphylococcus aureus (other cluster, CLOT)

\begin{tabular}{|c|c|c|c|c|c|c|c|c|c|}
\hline \multirow{2}{*}{$\begin{array}{l}\text { Genotype/ } \\
\text { variant }\end{array}$} & \multirow{2}{*}{$\begin{array}{c}\text { IMI } \\
{[\mathrm{BTM}]}\end{array}$} & \multicolumn{8}{|c|}{ No. of positive strains ${ }^{1}$} \\
\hline & & sea & $s e c$ & sed & seg & sei & sej & tst & lukEB \\
\hline A & $1[0]$ & 0 & 1 & 0 & 1 & 0 & 0 & 1 & 0 \\
\hline D & $1[0]$ & 0 & 0 & 0 & 1 & 0 & 0 & 0 & 0 \\
\hline E & $4[3]$ & $1[0]$ & 0 & $2[1]$ & $3[3]$ & $4[3]$ & $2[1]$ & 0 & $4[3]$ \\
\hline G & $1[0]$ & 0 & 1 & 0 & 0 & 0 & 0 & 1 & 1 \\
\hline $\mathrm{H}$ & $1[0]$ & 0 & 1 & 0 & 1 & 1 & 0 & 1 & 0 \\
\hline $\mathrm{J}$ & $1[1]$ & 0 & 0 & 0 & $1[0]$ & $1[0]$ & 0 & 0 & [1] \\
\hline $\mathrm{J}^{\mathrm{I}}$ & $0[1]$ & 0 & 0 & 0 & 0 & 0 & 0 & 0 & {$[1]$} \\
\hline $\mathrm{L}$ & $0[1]$ & 0 & 0 & 0 & 0 & 0 & 0 & 0 & [1] \\
\hline M & $2[1]$ & 0 & 0 & 0 & 0 & 0 & 0 & 0 & $2[1]$ \\
\hline $\mathrm{N}$ & $1[0]$ & 0 & 0 & 1 & 1 & 0 & 1 & 0 & 1 \\
\hline $\mathrm{O}$ & $2[0]$ & 0 & 0 & 1 & 1 & 0 & 0 & 0 & 1 \\
\hline $\mathrm{O}^{\mathrm{I}}$ & $1[0]$ & 0 & 0 & 0 & 1 & 1 & 0 & 0 & 0 \\
\hline $\mathrm{P}$ & $2[2]$ & 0 & 0 & 1 & $2[2]$ & $1[2]$ & 0 & 0 & 0 \\
\hline S & $3[7]$ & 0 & 0 & 0 & 0 & 0 & 0 & 0 & 0 \\
\hline$S^{I}$ & $3[0]$ & 0 & 0 & 0 & 1 & 1 & 0 & 0 & 3 \\
\hline $\mathrm{T}$ & $0[1]$ & 0 & {$[1]$} & 0 & {$[1]$} & {$[1]$} & 0 & 0 & 0 \\
\hline Y & $1[1]$ & 0 & 0 & 0 & $1[0]$ & $1[0]$ & 0 & 0 & 0 \\
\hline Z & $14[4]$ & 0 & $2[0]$ & 0 & $7[4]$ & $7[4]$ & 0 & $2[0]$ & $4[3]$ \\
\hline $\mathrm{AA}$ & $3[0]$ & 0 & 0 & 0 & 0 & 0 & 0 & 0 & 3 \\
\hline $\mathrm{AB}$ & $1[1]$ & 0 & $1[1]$ & 0 & $1[1]$ & $1[1]$ & 0 & $1[0]$ & 0 \\
\hline $\mathrm{AH}$ & $0[4]$ & {$[1]$} & 0 & 0 & {$[2]$} & {$[2]$} & 0 & {$[1]^{2}$} & {$[4]$} \\
\hline AK & $0[1]$ & 0 & 0 & 0 & {$[1]$} & {$[1]$} & 0 & 0 & 0 \\
\hline $\mathrm{AM}$ & $8[3]$ & $1[2]$ & $1[0]$ & 0 & $1[0]$ & $1[0]$ & 0 & $1[0]$ & $8[3]$ \\
\hline $\mathrm{AN}$ & $1[1]$ & 0 & 0 & 0 & 0 & 0 & 0 & 0 & $1[1]$ \\
\hline $\mathrm{AR}$ & $1[1]$ & 0 & 0 & 0 & $1[0]$ & $1[0]$ & 0 & 0 & 0 \\
\hline AS & $0[1]$ & 0 & 0 & 0 & 0 & 0 & 0 & 0 & {$[1]$} \\
\hline AT & $1[0]$ & 0 & 0 & 0 & 1 & 1 & 0 & 0 & 0 \\
\hline $\mathrm{AU}$ & $0[1]$ & 0 & 0 & 0 & 0 & {$[1]$} & 0 & 0 & {$[1]$} \\
\hline $\mathrm{AX}$ & $1[0]$ & 0 & 0 & 0 & 1 & 1 & 0 & 0 & 0 \\
\hline AY & $1[0]$ & 0 & 1 & 0 & 0 & 0 & 0 & 0 & 1 \\
\hline BA & $0[1]$ & 0 & 0 & 0 & 0 & 0 & 0 & 0 & {$[1]$} \\
\hline BB & $2[0]$ & 0 & 0 & 0 & 2 & 2 & 0 & 0 & 1 \\
\hline $\mathrm{BC}$ & $1[0]$ & 0 & 0 & 0 & 0 & 0 & 0 & 0 & 1 \\
\hline BE & $1[0]$ & 0 & 0 & 0 & 0 & 0 & 0 & 0 & 1 \\
\hline $\mathrm{BE}^{\mathrm{I}}$ & $2[0]$ & 0 & 0 & 0 & 1 & 1 & 0 & 1 & 1 \\
\hline $\mathrm{BF}$ & $0[1]$ & 0 & {$[1]$} & 0 & 0 & 0 & 0 & 0 & {$[1]$} \\
\hline BG & $2[5]$ & 0 & 0 & 0 & $2[4]$ & $2[4]$ & 0 & 0 & 0 \\
\hline $\mathrm{BH}$ & $0[1]$ & 0 & 0 & 0 & 0 & 0 & 0 & 0 & 0 \\
\hline BJ & $2[0]$ & 0 & 0 & 0 & 0 & 0 & 0 & 0 & 2 \\
\hline BL & $0[2]$ & 0 & 0 & 0 & 0 & 0 & 0 & 0 & {$[2]$} \\
\hline $\mathrm{BN}$ & $1[0]$ & 0 & 0 & 0 & 0 & 0 & 0 & 0 & 1 \\
\hline Total & $66[45]$ & $2[3]$ & $8[3]$ & $5[1]$ & $31[18]$ & $27[19]$ & $3[1]$ & $8[1]$ & $36[24]$ \\
\hline
\end{tabular}

${ }^{1}$ sea to $s e j=$ genes coding for staphylococcal enterotoxins A to J, respectively; tst = gene coding for the toxic shock syndrome toxin-1; lukEB = SNP within the lukE gene.

The coa amplicon size ranged between 549 and 652 bp. Comparing the size of the amplicons among countries in which at least 10 CLB strains had to be present (Table 5), we observed a significant difference between the Swiss (reference) and German $(P<0.001)$ and between the Swiss and Italian strains $(P<0.001)$. The median values for the Austrian and Swiss strains, however, were almost identical. All genotypic variants of CLB were involved in bovine IMI (Table 3).

\section{Cluster C}

This cluster was the largest and included 115 strains in total (Table 3); representatives were detected in al- most every country except for Macedonia and Slovenia (Table 5). All strains, whether isolated from SQM pools or from BTM, were negative for lukEB (Table 3). They were almost exclusively positive for seg and sei (BTM strains) and many were positive for sec (40\%) and tst (43\%). None of the other tested enterotoxin genes were observed. Variant GTC ${ }^{\mathrm{I}}$ was observed in Switzerland less frequently than in the other countries, and GTC ${ }^{\mathrm{II}}$ was only detected in Belgium and Germany. In addition, the virulence gene patterns of CLC among countries and the type of milk sample from which the strains were isolated (SQM pool vs. BTM) were compared by the GEE procedure. For covariates "country" and "sample type," the $P$-values were 0.776 and 0.902 , respectively. 


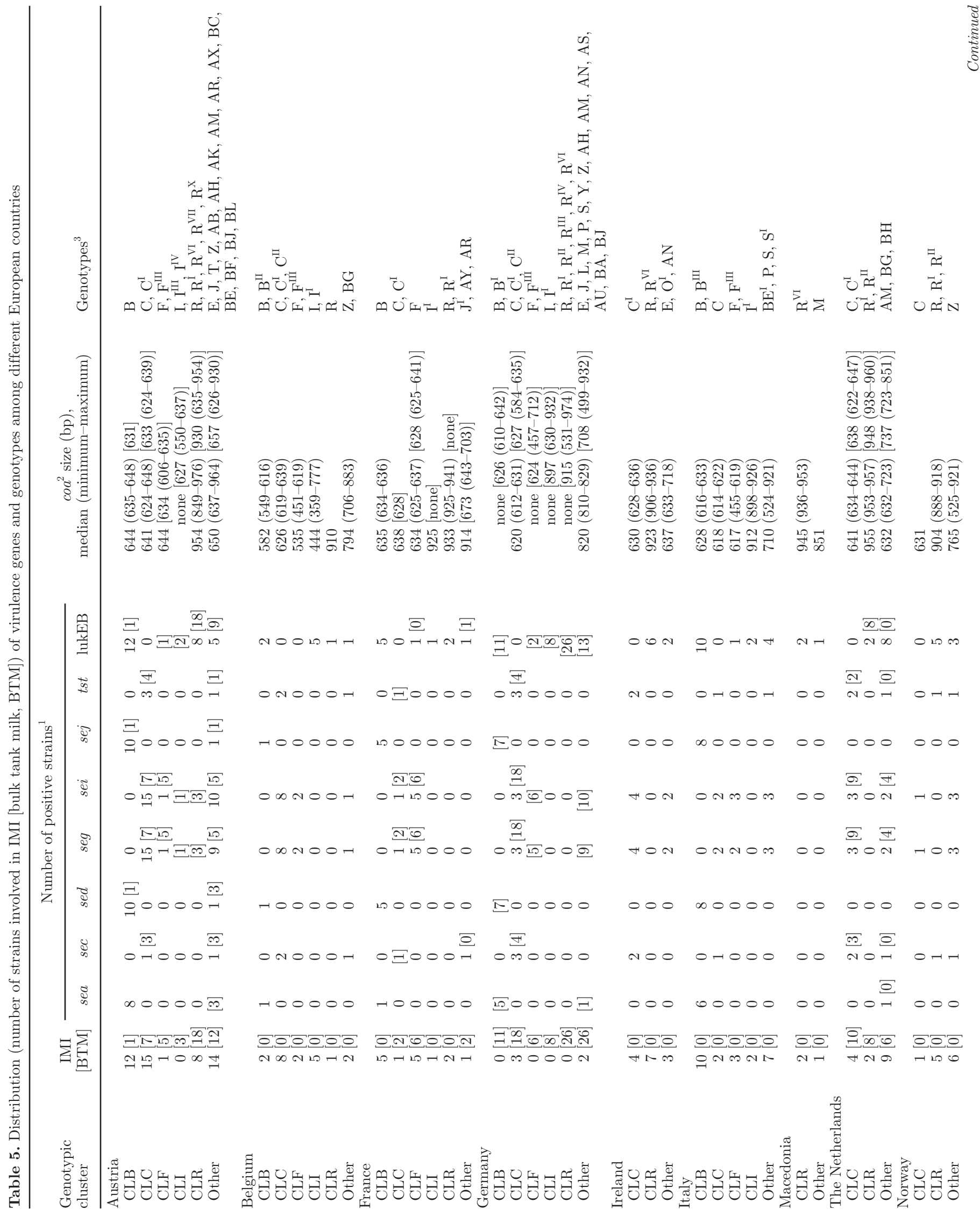




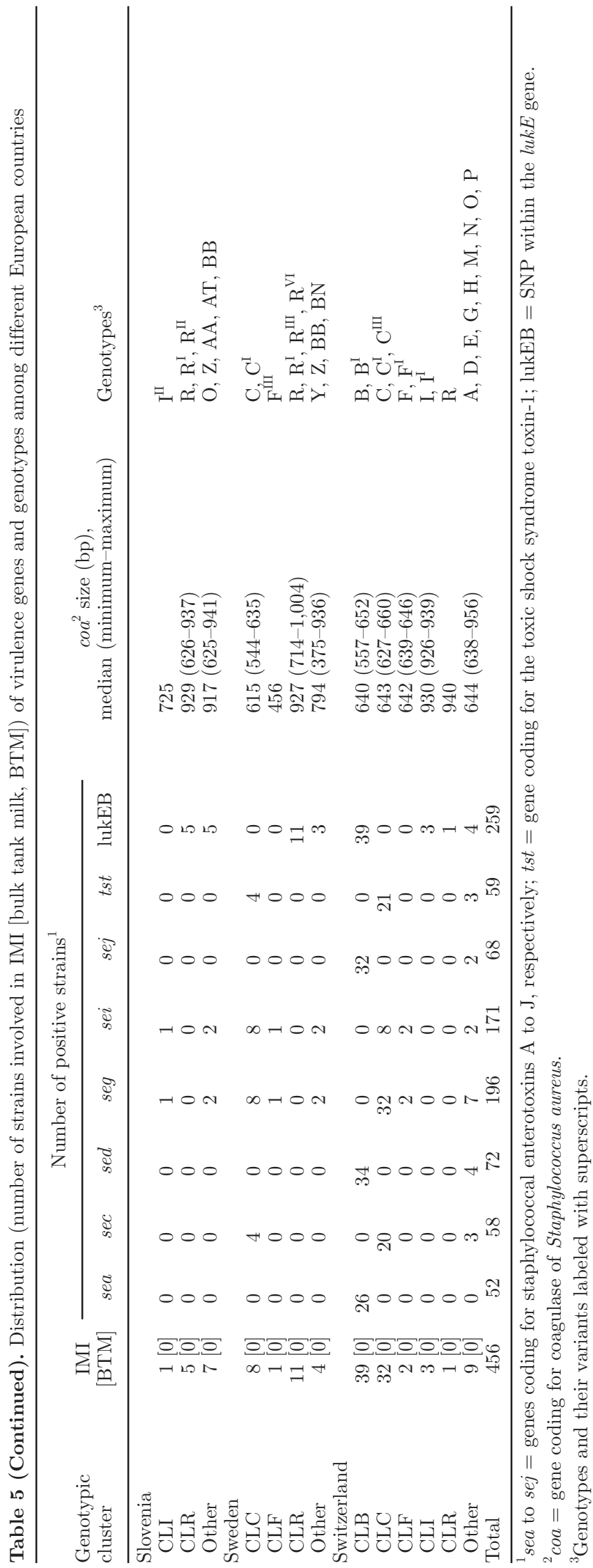

The size of the coa amplicons ranged between 544 and 660 bp (Table 3 ). The medians were very similar among IMI-associated and BTM strains (Table 3) and among countries (Table 5), except in the case of the German strains, where the median size of the coa amplicons was considerably smaller than that of the Swiss strains $(P$ $<0.001)$. Genotype C and variants $\mathrm{GTC}^{\mathrm{I}}, \mathrm{GTC}^{\mathrm{II}}$, and GTC $^{\text {III }}$ were all involved in bovine IMI (Table 3).

\section{Cluster $R$}

Strains of CLR (overall $\mathrm{n}=96$ ) were frequently observed and present in all countries except Italy (Table 5 ). With 8 variants in total (Table 3), CLR was the most divergent genotypic cluster. Most of the variants were described for the first time.

Except for 3 strains, CLR was characterized by the lack of all the analyzed enterotoxin genes. This observation was true for strains isolated from SQM pools and from BTM. They were almost exclusively positive for lukEB. For covariate "sample type," GEE analysis revealed a value of $P=0.443$. For covariate "country," GEE analysis was impossible (matrix singularity) as the virulence gene pattern differed minimally among the countries (Table 3). The medians of the coa amplicons were very similar among IMI-associated and BTM strains, resulting in values of 931 and $927 \mathrm{bp}$, respectively (Table 3 ). Genotype $\mathrm{R}$ and all of its variants except GTR $^{\text {IV }}$ and GTR ${ }^{\text {VII }}$ were involved in IMI (Table 3).

\section{Cluster F and Cluster I}

Compared with the previous clusters, CLF and CLI were considerably smaller, consisting overall of $31(7 \%)$ and $23(5 \%)$ strains, respectively (Table 3$)$. As shown in Table 5, strains of CLF were predominantly observed in France although they was also present in other countries. All CLF strains isolated from SQM pools and BTM (Table 3) tested positive for sei and most for seg. Genotype $\mathrm{F}$ was most frequently observed. The strains were normally lukEB-negative and the median size of coa for CLF was $628 \mathrm{bp}$ for strains involved in IMI and 630 bp for strains from BTM (Table 3), respectively. Genotype $\mathrm{F}$ and its variants were all involved in bovine IMI (Table 3).

For CLI, the corresponding strains were mainly detected in Belgium and Germany (Table 5). Genotype I and variants $\mathrm{GTI}^{\mathrm{I}}$ and $\mathrm{GTI}^{\mathrm{IV}}$ were highly consistent in their genetic properties - all were negative for all the analyzed enterotoxin genes and all were positive for lukEB (Table 3). In contrast, $\mathrm{GTI}^{\mathrm{II}}$ and $\mathrm{GTI}^{\mathrm{III}}$ (one strain each) were positive for sei and seg and negative for lukEB. For CLI, the median sizes of coa were 
$838 \mathrm{bp}$ (IMI-associated) and $891 \mathrm{bp}$ (BTM); IMI were observed for GTI, GTI ${ }^{\mathrm{I}}$ and GTI ${ }^{\mathrm{II}}$ (Table 3 ).

Regarding the covariate "sample type," GEE analysis revealed for CLI and CLF P-values of 0.841 and 0.947, respectively. For covariate "country," GEE analysis was impossible (matrix singularity) as for both CL the virulence gene patterns differed minimally among the countries (Table 3).

\section{Other Genotypes (CLOT)}

In total, 111 (24\%) CLOT strains were detected (Table 4). They included 41 genotypes and variants, with each comprising overall less than $5 \%$ of the total strains $(\mathrm{n}=456)$. Many were observed only once or twice (Table 4).

Considering the genotypes originally described in Switzerland (GTA, GTD, GTE, GTG, GTH, GTJ, GTL, GTM, GTN, GTO, GTP), they and their variants were sporadically detected in the other countries. Genotype A was only observed in Switzerland (Table 5); GTE was detected in Austria, Ireland, Germany, and Switzerland but the GTE strains were not constant in their virulence gene pattern (Table 4). Most of the GTE were positive for seg, sei, and lukEB, one strain was positive for sea, and 3 were positive for sed and $s e j$. The genetic properties of the most frequent CLOT genotypes, GTS $(\mathrm{n}=10)$, GTZ $(\mathrm{n}=18)$, GTAM $(\mathrm{n}=$ 11), are outlined below. None of the GTS had the analyzed enterotoxin genes and were negative for lukEB, regardless of whether the strains had been isolated from SQM pools or from BTM (Table 4). Eleven out of 18 GTZ strains (61\%) were positive for seg and sei, and 2 were positive for sec and tst. The GTZ strains were inconsistent with respect to lukEB. All of the GTAM strains were positive for lukEB and usually negative for the analyzed enterotoxin genes. In 3 cases, the sea gene was observed, and in 1 case, the combination of sec, seg, sei, and tst was observed; the virulence gene pattern, however, was inconsistent. For GTBG, some of the strains were positive for seg and sei, whereas all of them were lukEB-negative. Interestingly, GTAM and GTBG were both restricted to certain countries. In the case of GTAM, it was observed in Austria, Germany, and the Netherlands whereas GTBG was only detected in Belgium and the Netherlands.

Considering CLOT, various genotypes and their variants $(\mathrm{n}=30)$ were involved in bovine IMI (Table 4). For the remaining genotypes, no association could be made as they were isolated from BTM.

\section{DISCUSSION}

This study demonstrates that the same bovine genotypes of Staph. aureus detected in Switzerland are also present in other European countries. The 2 most important genotypic clusters for Switzerland, CLB and CLC, were also frequently detected in several of these countries and were characterized by the same genetic properties as the Swiss clusters. The same was true for other clusters such as CLF and CLI.

In total, 12 countries from the north to the south of Europe participated in the present study. The samples comprised SQM, BTM, and strains from the authors' strain collections (BC). They were largely obtained from the collection area of the collaborators. As a consequence, the samples do not allow representative conclusions to be drawn about the presence and frequency of the various staphylococcal subtypes within and between countries. The main goal of the present study was, however, to obtain a unified view about the presence of bovine staphylococcal genotypes in European countries and to investigate whether these genotypes observed were identical to the Swiss ones with respect to their genetic characteristics (virulence gene patterns). If so, the within-herd epidemiological and pathogenic properties for the particular subtypes detected in Switzerland (Fournier et al., 2008; Graber et al., 2009) are expected to be valid for the other countries.

For all major CL (CLB, CLC, CLF, CLI, CLR), GEE analysis revealed high to very high $P$-values for both covariates (country and sample type). This means that for each major CL, the virulence gene patterns did not differ systematically among countries and they were the same whether the strains were isolated from SQM pools or from BTM. At first glance, the latter result is surprising, because BTM may contain Staph. aureus originating from not only cows with IMI, but also from their environment. However, this result is feasible if the quantities of Staph. aureus contributed by both sources are considered. In the case of Staph. aureus shed in milk, the average amount is $5.9 \times 10^{3} \mathrm{cfu} / \mathrm{mL}$ and may reach values up to $2.2 \times 10^{7}$ (Studer et al., 2008). In the case of Staph. aureus to be isolated from environmental sources (cow surfaces, milking equipment, bedding, humans), however, enrichment procedures are required (Matos et al., 1991; authors' experience) as the quantities are very low in these samples. Consequently, it is very likely that the Staph. aureus present in the BTM sample and on the agar plate originated from cows with staphylococcal IMI. These considerations are confirmed by Sears and McCarthy (2003), who stated that the principal and overwhelming source for Staph. aureus is the infected gland of cows on the farms.

The results demonstrate that CLB is not restricted to Switzerland but is also present in at least 5 other countries (Austria, Belgium, France, Germany, Italy). Interestingly, they are all situated in central Europe. These findings may result from the traditionally inten- 
sive cattle movement particularly among Switzerland and its border areas to the adjacent regions of northern Italy, eastern France, southern Germany (BadenWürttemberg), and western Austria. Interestingly, CLB was never observed in the north (Niedersachsen) or middle (Thüringen) regions of Germany although BTM was, by far, the most important sample type for all 3 sampled regions in Germany and the numbers of BTM samples analyzed for Baden-Württemberg and Niedersachsen were similar. Factors other than animal transfer may also be involved. Indeed, sampling was not representative for most of the participating countries and the size and type of the samples differed among the countries, factors that may contribute to underestimating the true prevalence of Staph. aureus genotypes and may explain the absence of Staph. aureus GTB in some countries. However, if Staph. aureus GTB was present in SQM pools or in BTM, 10 colonies could always be picked and these colonies were almost exclusively positive for GTB. These results confirm the theoretical considerations on the detection of this genotype in milk (see Material and Methods) and show that this genotype could be reliably detected if it was present in these samples. In addition, GTB was never observed in the Swedish BC strains although, if present in a country, Staph. aureus GTB is frequently detected in clinical milk samples (Fournier et al., 2008). Therefore, these findings, together with the results from Germany, support a more localized, middle European distribution of this genotype. For further clarification, however, representative studies for each country separately are necessary. Such a study was recently performed in Switzerland and analyzed 223 BTM samples stratified among the number of dairy herds per canton (H. U. Graber, unpublished data). Those analyses demonstrated that $10.3 \%$ of the herds (approximately 3,300 herds countrywide) were affected with Staph. aureus GTB. The same investigations further revealed local differences in the herd prevalence for Staph. aureus GTB in Switzerland.

In contrast to the rather regional occurrence of CLB, the clusters CLC, CLF, CLI, and CLR were detected almost in any country involved. This is particularly true for CLR, which forms a large cluster containing 8 variants and was frequently observed throughout Europe except in Switzerland, where only one strain has been found so far (even though the Swiss strain collection is large). This ubiquitous occurrence of CLR, but also of CLC, CLF, and CLI, is in clear contrast to the findings for CLB. The straight-line distances between Milan (Italy) and Dublin (Ireland), Oslo (Norway), or Stockholm (Sweden) exceed 1,400 km and include sea crossings, significantly hindering animal movement. If animal movement, however, is the only driving force for spreading of Staph. aureus among cattle, the spreading process for CLC, CLF, CLI, and CLR must have been started a long time ago so that a steady state exists today within Europe. Further investigations, however, are necessary to elucidate the phenomenon of the different spread of the genotypes.

In addition to the exemplified clusters, a considerable number of other genotypes were found (CLOT), $61 \%$ of which were observed only once (Table 4 ). More frequently detected genotypes were GTS, GTZ, and GTAM but their occurrence was still rare $(<5 \%$ each). These findings, however, do not rule out some CLOT genotypes being more prominent in specific countries. This was particularly true for GTS (observed only in Germany and Italy), GTAH (Austria), or GTAM (the Netherlands).

The findings of the present study confirm the results previously observed in Switzerland (Fournier et al., 2008): on the one hand, a few predominant clusters (CLB, CLC, CLF, CLI, CLR) made up a large proportion of all strains $(76 \%)$. On the other hand, many other genotypes were found (CLOT), but each was rare. Interestingly, all the predominant clusters and 30 out of the 41 rare genotypes (CLOT) were involved in IMI.

The large variety of these latter genotypes and their rare occurrence favors the hypothesis that all genotypes of Staph. aureus and their variants are able to cause bovine IMI. In the case of the CLOT strains, however, animal and environmental risk factors are assumed vital for developing IMI. Considering the major CL strains, these factors are supposed to be less important, probably because these strains are more adapted to cattle and are more pathogenic. However, this is a hypothesis and, like similar hypotheses (e.g., Zadoks and Fitzpatrick, 2009), needs to be confirmed by adequate studies.

It is striking that the strains of CLB, CLC, CLF, CLI, and CLR generally showed the same virulence gene patterns and the lukEB polymorphisms as the Swiss strains. Based on this very high genetic conservation within genotypic clusters, we can hypothesize that strains within the same CL show the same epidemiological and pathogenic properties as the Swiss strains, although minor country-specific modifications may occur because of local strain evolution, as shown by the analysis of the coa polymorphism. Indeed, our hypothesis is supported by findings from Italy which demonstrate that strains of CLB are actually strongly associated with contagious IMI in Italian farms, whereas GTC is associated with individual cow disease (Cremonesi et al., 2015). The results of the current study, however, do not exclude the possibility that in countries where CLB was not detected, other genotypes may be involved in contagious IMI. 


\section{CONCLUSIONS}

Staphylococcus aureus was observed in all 12 European countries included in the present study. Analysis of a large collection of strains $(\mathrm{n}=456)$ revealed 5 major genotypic clusters, CLB, CLC, CLF, CLI, and CLR, representing $76 \%$ of all isolates, of which CLB, CLC, and CLR were by far the most prominent. The remaining $24 \%$ belonged to 41 different genotypes and variants. All of these were rarely observed, with several being observed only once. Clusters CLC and CLR were found in almost every country, whereas CLB was restricted to central Europe. Almost all genotypes previously detected in Switzerland were also present in one or more other countries. The results further demonstrated a high association between genotypes and virulence gene patterns based on the presence of various enterotoxin genes and gene polymorphisms.

\section{ACKNOWLEDGMENTS}

The authors thank D. Dietrich, Swiss Group for Clinical Cancer Research (Berne, Switzerland), for his advice and support in statistical analysis. The study was supported by a grant of the Swiss Federal Veterinary Office (Berne, Switzerland).

\section{REFERENCES}

Akineden, O., C. Annemüller, A. A. Hassan, C. Lämmler, W. Wolter, and M. Zschöck. 2001. Toxin genes and other characteristics of Staphylococcus aureus isolates from milk of cows with mastitis. Clin. Diagn. Lab. Immunol. 8:959-964.

Boss, R., J. Naskova, A. Steiner, and H. U. Graber. 2011. Mastitis diagnostics: Quantitative PCR for Staphylococcus aureus genotype B in bulk tank milk. J. Dairy Sci. 94:128-137.

Brakstad, O. G., K. Aasbakk, and J. A. Maeland. 1992. Detection of Staphylococcus aureus by polymerase chain reaction amplification of the nuc gene. J. Clin. Microbiol. 30:1654-1660.

Cremonesi, P., F. Pozzi, M. Raschetti, G. Bignoli, E. Capra, H. U. Graber, F. Vezzoli, R. Piccinini, B. Bertasi, S. Biffani, B. Castiglioni, and M. Luini. 2015. Genomic characteristics of Staphylococcus aureus strains associated with high within-herd prevalence of intramammary infections in dairy cows. J. Dairy Sci. 98:6828-6838.

Enright, M. C., N. P. Day, C. E. Davies, S. J. Peacock, and B. G. Spratt. 2000. Multilocus sequence typing for characterization of methicillin-resistant and methicillin-susceptible clones of Staphylococcus aureus. J. Clin. Microbiol. 38:1008-1015.

Fournier, C., P. Kuhnert, J. Frey, R. Miserez, M. Kirchhofer, T. Kaufmann, A. Steiner, and H. U. Graber. 2008. Bovine Staphylococcus aureus: association of virulence genes, genotypes and clinical outcome. Res. Vet. Sci. 85:439-448.

Graber, H. U., M. G. Casey, J. Naskova, A. Steiner, and W. Schaeren. 2007. Development of a highly sensitive and specific assay to detect Staphylococcus aureus in bovine mastitic milk. J. Dairy Sci. 90:4661-4669.

Graber, H. U., J. Naskova, E. Studer, T. Kaufmann, M. Kirchhofer, M. Brechbuhl, W. Schaeren, A. Steiner, and C. Fournier. 2009. Mastitis-related subtypes of bovine Staphylococcus aureus are characterized by different clinical properties. J. Dairy Sci. 92:1442-1451.
Graber, H. U., S. Pfister, P. Burgener, R. Boss, M. Meylan, and J. Hummerjohann. 2013. Bovine Staphylococcus aureus: Diagnostic properties of specific media. Res. Vet. Sci. 95:38-44.

Harmsen, D., H. Claus, W. Witte, J. Rothganger, H. Claus, D. Turnwald, and U. Vogel. 2003. Typing of methicillin-resistant Staphylococcus aureus in a university hospital setting by using novel software for spa repeat determination and database management. J. Clin. Microbiol. 41:5442-5448.

Holm, S. 1979. A simple sequentially rejective multiple test procedure. Scand. J. Stat. 6:65-70.

Hwang, S. Y., Y. K. Park, H. C. Koo, and Y. H. Park. 2010. spa typing and enterotoxin gene profile of Staphylococcus aureus isolated from bovine raw milk in Korea. J. Vet. Sci. 11:125-131.

Jensen, M. A., J. A. Webster, and N. Straus. 1993. Rapid identification of bacteria on the basis of polymerase chain reaction-amplified ribosomal DNA spacer polymorphisms. Appl. Environ. Microbiol. 59:945-952.

Liang, K. Y., and S. L. Zeger. 1986. Longitudinal data analysis using generalized linear models. Biometrika 73:13-22.

Matos, J. S., D. G. White, R. J. Harmon, and B. E. Langlois. 1991. Isolation of Staphylococcus aureus from sites other than the lactating mammary gland. J. Dairy Sci. 74:1544-1549.

Monday, S. R., and G. A. Bohach. 1999. Use of multiplex PCR to detect classical and newly described pyrogenic toxin genes in staphylococcal isolates. J. Clin. Microbiol. 37:3411-3414.

NMC (National Mastitis Council). 1999. Laboratory Handbook on Bovine Mastitis. Rev. ed. National Mastitis Council Inc., Madison, WI.

R Core Team. 2013. R: A Language and Environment for Statistical Computing. R Foundation for Statistical Computing, Vienna, Austria.

Rabello, R. F., B. M. Moreira, R. M. Lopes, L. M. Teixeira, L. W. Riley, and A. C. Castro. 2007. Multilocus sequence typing of Staphylococcus aureus isolates recovered from cows with mastitis in Brazilian dairy herds. J. Med. Microbiol. 56:1505-1511.

Sakwinska, O., D. Morisset, J. Y. Madec, A. Waldvogel, P. Moreillon, and M. Haenni. 2011. Link between genotype and antimicrobial resistance in bovine mastitis-related Staphylococcus aureus strains, determined by comparing Swiss and French isolates from the Rhone Valley. Appl. Environ. Microbiol. 77:3428-3432.

Sears, P. M., and K. K. McCarthy. 2003. Management and treatment of staphylococcal mastitis. Vet. Clin. North Am. Food Anim. Pract. 19:171-185.

Studer, E., W. Schaeren, J. Naskova, H. Pfaeffli, T. Kaufmann, M. Kirchhofer, A. Steiner, and H. U. Graber. 2008. A longitudinal field study to evaluate the diagnostic properties of a QPCR based assay to detect Staphylococcus aureus in milk. J. Dairy Sci. 91:1893-1902.

Syring, C., R. Boss, M. Reist, M. Bodmer, J. Hummerjohann, P. Gehrig, and H. U. Graber. 2012. Bovine mastitis: The diagnostic properties of a PCR-based assay to monitor the Staphylococcus aureus genotype B status of a herd, using bulk tank milk. J. Dairy Sci. 95:3674-3682.

Tavakol, M., R. G. Riekerink, O. C. Sampimon, W. J. van Wamel, A. van Belkum, and T. J. Lam. 2012. Bovine-associated MRSA ST398 in the Netherlands. Acta Vet. Scand. 54:28.

van den Borne, B. H., M. Nielen, G. van Schaik, M. B. Melchior, T. J. Lam, and R. N. Zadoks. 2010. Host adaptation of bovine Staphylococcus aureus seems associated with bacteriological cure after lactational antimicrobial treatment. J. Dairy Sci. 93:2550-2558.

Zadoks, R., and J. Fitzpatrick. 2009. Changing trends in mastitis. Ir. Vet. J. 62(Suppl. 4):S59-70.

Zadoks, R., W. van Leeuwen, H. Barkema, O. Sampimon, H. Verbrugh, Y. H. Schukken, and A. van Belkum. 2000. Application of pulsed-field gel electrophoresis and binary typing as tools in veterinary clinical microbiology and molecular epidemiologic analysis of bovine and human Staphylococcus aureus isolates. J. Clin. Microbiol. 38:1931-1939. 